Article

\title{
Sodium and Potassium Intakes and Cardiovascular Risk Profiles in Childhood Cancer Survivors: The SCCSS-Nutrition Study
}

\author{
Fabiën N. Belle ${ }^{1,2, *(D)}$, Christina Schindera ${ }^{1,3,4}$, Idris Guessous ${ }^{5}$, Maja Beck Popovic ${ }^{6}$, \\ Marc Ansari ${ }^{7,8}$, Claudia E. Kuehni ${ }^{1,4}{ }^{(}$and Murielle Bochud ${ }^{2}$ \\ 1 Institute of Social and Preventive Medicine (ISPM), University of Bern, 3012 Bern, Switzerland \\ 2 Center for Primary Care and Public Health (Unisanté), University of Lausanne, 1010 Lausanne, Switzerland \\ 3 University Children's Hospital Basel (UKBB), 4056 Basel, Switzerland \\ 4 Pediatric Oncology, Children's University Hospital of Bern, University of Bern, 3010 Bern, Switzerland \\ 5 Division and Department of Primary Care Medicine, Geneva University Hospital HUG, \\ 1205 Geneva, Switzerland \\ 6 Pediatric Hematology-Oncology unit, Lausanne University Hospital CHUV, 1011 Lausanne, Switzerland \\ 7 Pediatrics Onco-Hematology Unit, Geneva University Hospital HUG, 1205 Geneva, Switzerland \\ 8 Cansearch Research laboratory, 1205, Geneva Medical School, 1205 Geneva, Switzerland \\ * Correspondence: fabien.belle@ispm.unibe.ch; Tel.: +41-31-631-33-47
}

Received: 15 October 2019; Accepted: 17 December 2019; Published: 24 December 2019

check for updates

\begin{abstract}
Risk of cardiovascular disease (CVD), common in childhood cancer survivors (CCSs), may be affected by diet. We assessed sodium (Na) and potassium (K) intake, estimated from food frequency questionnaires (FFQs) and morning urine spots, and its associations with cardiovascular risk in CCSs. We stratified CCSs into three risk profiles based on (A) personal history (CVD, CVD risk factors, or CVD risk-free), (B) body mass index (obese, overweight, or normal/underweight), and (C) cardiotoxic treatment (anthracyclines and/or chest irradiation, or neither). We obtained an FFQ from 802 and sent a spot urine sample collection kit to 212 , of which $111(52 \%)$ returned. We estimated $\mathrm{Na}$ intake $2.9 \mathrm{~g} /$ day based on spot urine and $2.8 \mathrm{~g}$ /day based on FFQ; the estimated $\mathrm{K}$ intake was $1.6 \mathrm{~g} /$ day (spot urine) and $2.7 \mathrm{~g} /$ day (FFQ). CCSs with CVD risk factors had a slightly higher Na intake ( $3.3 \mathrm{~g} /$ day), than CCSs risk free ( $2.9 \mathrm{~g} /$ day) or with CVD ( $2.7 \mathrm{~g} /$ day, $p=0.017)$, and obese participants had higher Na intake (4.2 g/day) than normal/underweight CCSs (2.7 g/day, $p<0.001)$. Daily Na intake was above, and daily $\mathrm{K}$ intake below, the national recommended levels. Adult survivors of childhood cancer need dietary assistance to reduce $\mathrm{Na}$ and increase $\mathrm{K}$ intake.
\end{abstract}

Keywords: sodium; potassium; nutrition; diet; urine spot; food frequency questionnaire; cardiovascular disease; childhood cancer survivors; Swiss Childhood Cancer Registry; Europe

\section{Introduction}

Cardiovascular disease (CVD) is the leading non-malignant cause of death in childhood cancer survivors (CCSs) [1-3]. CVD can be caused by cancer treatment and occurs prematurely in CCSs and increases with age without plateauing over time, leading to high morbidity and mortality [4]. Cardiotoxic cancer treatment includes chemotherapy with anthracyclines and chest irradiation $[5,6]$. Anthracyclines increase the risk of heart failure and chest irradiation is associated with heart failure, 
valvular disease, coronary artery disease, and atrial fibrillation [6,7]. In the US, CCSs are seven times as likely to die from a cardiac-related event than members of the general population [5]. Thirteen percent of CCSs exposed to cardiotoxic treatments suffered a life-threatening cardiovascular event in the 30 years after cancer treatment [8]. In the general population, hypertension, obesity, diabetes mellitus, smoking, and dyslipidemia are primary contributors to CVD [9-11]. These risk factors are also relevant for CCSs and represent important modifiable factors in the development and severity of CVD [12-14]. Efforts to reduce the obesity epidemic are an important pillar of cardiovascular prevention in the general population [9]. In CCSs, obesity management may substantially reduce the risk of premature cardiac risk: obese CCSs who received cardiotoxic treatment have a nine-times higher risk of developing coronary artery disease, higher than expected under an additive assumption [13].

Diets low in sodium $(\mathrm{Na})$ and high in potassium $(\mathrm{K})$ have been shown to reduce blood pressure and lower the risk of cardiovascular events and mortality in the general adult population [10,15-17]. The World Health Organization (WHO) recommends restricting Na intake $(<2 \mathrm{~g} /$ day) and increasing K intake (>3.5 g/day) [16,17] but high sodium consumption is still common $[15,18]$, particularly among obese persons $[19,20]$, and may pose particular problems for CCSs, since their background CVD risk is higher. We know surprisingly little about the dietary intake of Na and K among CCSs, so we set out to assess $\mathrm{Na}$ and $\mathrm{K}$ intakes of CCSs based on FFQs and morning fasting urine spot samples. Urinary $\mathrm{Na}$ excretion, whether in spot urine or in $24 \mathrm{~h}$ collection, is a recognized biomarker of Na intake. In spot urine, the Na:creatinine (Cre) ratio needs to be used to account for urine concentration. Urinary $\mathrm{Na}: \mathrm{K}$ ratio in spot or $24 \mathrm{~h}$ urine is a biomarker of $\mathrm{Na}$ and $\mathrm{K}$ intake that is strongly and positively associated with CVD risk. We determine if $\mathrm{Na}$ and $\mathrm{K}$ intakes are associated with CVD and modifiable cardiovascular risk factors.

\section{Materials and Methods}

\subsection{Study Populations}

The Swiss Childhood Cancer Survivor Study

The Swiss Childhood Cancer Survivor Study (SCCSS) is a population-based, long-term follow-up study of all childhood cancer patients registered in the Swiss Childhood Cancer Registry (SCCR) with leukemia, lymphoma, central nervous system tumors, malignant solid tumors, or Langerhans cell histiocytosis diagnosed in Switzerland. Participants were under the age of 21 years at the time of diagnosis, survived five years or more after the initial diagnosis of cancer, and were alive at the time of the study [21-23]. Ethical approval of the SCCSS and the SCCR was granted by the Ethics Committee of the Canton of Bern (KEK-BE: 166/2014); the SCCSS is registered at clinicaltrials.gov (NCT03297034).

CCSs were eligible to participate in the SCCSS-Nutrition study if they had childhood cancer diagnosed between 1976 and 2005, completed a baseline SCCSS questionnaire between 2007 and 2013 [21], and were 21 years of age or older at the time of follow-up survey in 2017. We sent a follow-up questionnaire that included an FFQ to all CCSs who were enrolled in SCCSS-Nutrition. We invited CCSs who returned the questionnaire and who lived in the French-speaking part of Switzerland to provide a urine spot sample (Figure 1). Detailed information on the SCCSS-Nutrition study design can be found in a prior publication [24]. 


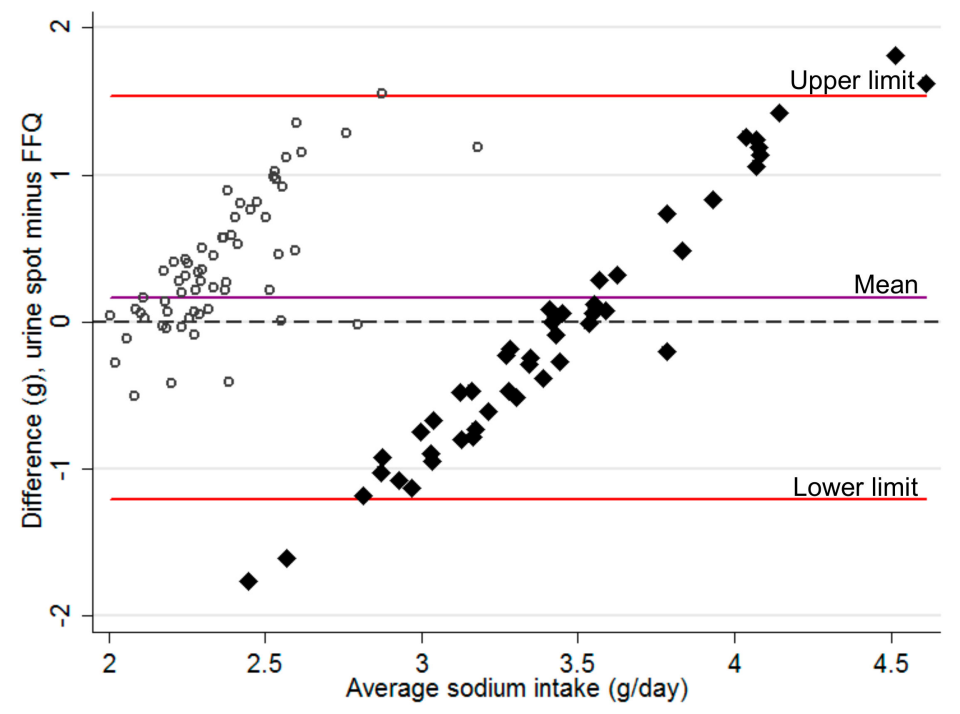

(a)

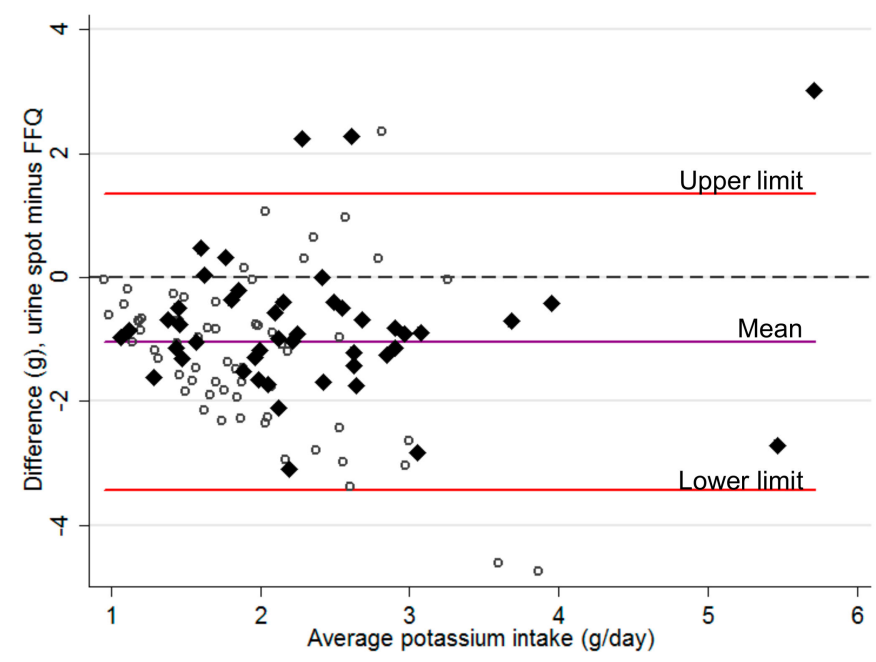

(b)

Figure 1. Bland-Altman plot of (a) average sodium and (b) potassium intake based on the intake calculated with a food frequency questionnaire ${ }^{1}$ and a morning fasting spot urine in 111 childhood cancer survivors of the SCCSS-Nutrition study. FFQ—-food frequency questionnaire; SCCSS—Swiss Childhood Cancer Survivor Study. $Y=0$ is the line of perfect average agreement, the hollow circles $(\mathrm{O})$ represent females and the black diamonds $(\$)$ represent males. ${ }^{1}$ Sodium $(\mathrm{Na})$ intake based on food frequency questionnaire $(\mathrm{FFQ})$ data was calculated with the equation: $(8.20+0.38 \times \mathrm{FFQ}$ in males)/2.54 and $(4.55+0.67 \times \mathrm{FFQ}$ in females) $/ 2.54$, with $1 \mathrm{~g} \mathrm{Na}=2.54 \mathrm{~g}$ salt $(\mathrm{NaCl})$ [25]. Na intake is clustered by sex due to this equation. Intake based on FFQ data only gives a mean daily intake of $1.9 \mathrm{~g} \pm 0.8$.

\subsection{Measurements}

\subsubsection{Food Frequency Questionnaire}

We assessed CCSs' dietary intake, including information on portion sizes, with a self-administered, semiquantitative FFQ [26-28] originally developed and validated against 24-hour dietary recalls for the adult French-speaking Swiss population $[25,26,29,30]$. We extended the FFQ for CCSs with 15 additional food items, based on 24-hour dietary recall data from the Swiss National Nutrition Survey [31]. We investigated whether foods most frequently consumed in the German and Italian-speaking parts of Switzerland were also included in the FFQ and added 15 more food items in the FFQ that were 
reported more than 70 times ( $>2 \%$ of the total food items) during the 24-hour dietary recalls. The FFQ solicits information on consumption frequency and portion sizes for 112 fresh and prepared food items in 13 food groups (dietary supplements not included) during the four previous weeks. Consumption frequency ranges from "never during the last four weeks" to "two or more times per day"; portions can be equal to, smaller than or larger than a reference size. Reference portions were defined as common household measures representing the median portion size of a previous validation study performed with 24-hour dietary recalls [30]. The smaller and larger portion sizes represented the first and third quartiles of this distribution. When we used the FFQ before, we did not calculate daily Na and K intake [32], so we combined two sources to convert the food portions into macro- and micronutrients: the French Information Center on Food Quality (Centre d'Information sur la Qualité des Aliments, CIQUAL, Maisons-Alfort Cedex, France) and the Swiss Food Composition Database of the Federal Food Safety and Veterinary Office [25,33,34].

We calculated daily Na intake two ways: (1) by summing up the Na content of each FFQ food item, and (2) by using the equation developed specifically for this FFQ for males and females separately [25]:

$$
\begin{aligned}
& \text { Males: }(8.20+0.38 \times \mathrm{Na}(\mathrm{g} / \text { day }) \text { from FFQ }) / 2.54 \\
& \text { Females: }(4.55+0.67 \times \mathrm{Na}(\mathrm{g} / \text { day }) \text { from FFQ }) / 2.54
\end{aligned}
$$

This equation is based on calibrations on total salt intake from 24-hour urine collections in a validation study that included 100 healthy people. We converted salt intake into Na intake, $1 \mathrm{~g} \mathrm{Na}$ is equal to $2.54 \mathrm{~g}$ of salt $(\mathrm{NaCl})[35]$.

\subsubsection{Sodium and Potassium Excretion Based on Morning Spot Urine}

We asked CCSs living in the French-speaking part of Switzerland who returned the FFQ to collect a morning fasting urine spot sample and to send their sample by post to the pediatric hematology-oncology unit of Lausanne University Hospital, Lausanne, Switzerland. Upon arrival, technicians used validated routine laboratory procedures to measure levels of $\mathrm{Na}$, $\mathrm{K}$, and Cre. We used the International Cooperative Study on Salt, Other Factors, and Blood Pressure (INTERSALT) equation to estimate 24-hour urinary $\mathrm{Na}$ excretion from a morning fasting spot sample (Sp) as a marker for $\mathrm{Na}$ intake [36]. In this equation, urine Cre from the spot is needed to account for the urine concentration level of the spot.

We estimated 24-hour urinary Na excretion (g/day) for males and females:

$$
\text { Males : } 23 \times \frac{\left[25.46+0.46 \times \operatorname{SpNa}\left(\frac{m m o l}{L}\right)-2.75 \times \operatorname{SpCre}\left(\frac{m m o l}{L}\right)-0.13 \times \operatorname{SpK}\left(\frac{m m o l}{L}\right)+4.10 \times B M I\left(\frac{\mathrm{kg}}{\mathrm{m}^{2}}\right)+0.26 \times \text { age }(y r s)\right]}{1000}
$$

$$
\text { Females : } 23 \times \frac{\left[5.07+0.34 \times \operatorname{SpNa}\left(\frac{\mathrm{mmol}}{L}\right)-2.16 \times \operatorname{SpCre}\left(\frac{\mathrm{mmmol}}{L}\right)-0.09 \times \operatorname{SpK}\left(\frac{\mathrm{mmol}}{\mathrm{L}}\right)+2.39 \times B M I\left(\frac{\mathrm{kg}}{\mathrm{m}^{2}}\right)+2.35 \times \text { age }(\mathrm{yrs})-0.03 \times \mathrm{age}^{2}\right]}{1000}
$$

We used the combined Pan American Health Organization (PAHO)/Chronic Kidney Disease Epidemiology Collaboration (CKD-EPI) equation to estimate 24-hour urinary K excretion (g/day) from a morning fasting spot sample as a marker for $\mathrm{K}$ intake [10,37]. PAHO, to estimate 24-hour urinary $\mathrm{K}$ excretion (g/day): $\frac{\left(\left(\frac{\text { measured spot urine } K}{\text { measured spot urine Cre }}\right) x \text { estimated 24-hour urinary Cre }\right) x 39.1}{1000}$, and CKD-EPI to estimate 24-hour urinary Cre excretion $(\mathrm{mg} /$ day): $879.89+12.51 \times$ weight $(\mathrm{kg})-6.19 \times$ age $(\mathrm{yrs})+(34.51$, if black $)-$ (379.42, if female).

\subsubsection{Sociodemographic, Lifestyle, and Clinical Characteristics}

For all CCSs, we collected data on sex, age, country of birth, education, living situation, physical activity, smoking status, and body mass index (BMI) from the SCCR and the questionnaires. We calculated BMI by dividing weight in kilograms by height in meters squared $\left(\mathrm{kg} / \mathrm{m}^{2}\right)$ based on self-reported weight without clothes and height without shoes at the time of the FFQ survey. 
BMI was underweight $\left(<18.5 \mathrm{~kg} / \mathrm{m}^{2}\right)$, normal $\left(18.5-24.9 \mathrm{~kg} / \mathrm{m}^{2}\right)$, overweight $\left(25-29.9 \mathrm{~kg} / \mathrm{m}^{2}\right)$, or obese $\left(\geq 30 \mathrm{~kg} / \mathrm{m}^{2}\right)$ [38]. We also extracted additional clinical information from the SCCR including information on cancer diagnosis, age at diagnosis, and time since diagnosis. Diagnosis was classified according to the International Classification of Childhood Cancer, 3rd Edition (ICCC-3) [39]. Irradiation was classified as any irradiation or as cardiotoxic chest irradiation related to the original cancer diagnosis. Chest irradiation included mantlefield irradiation, irradiation of the thorax, mediastinum or thoracic spine, or total body irradiation. We collected a cumulative dosage of chest irradiation from medical records and categorized it based on the Children's Oncology Group Long-Term Follow-up (COG-LTFU) guidelines for cardiology follow-up consultation. Chest irradiation was categorized as $<30$ Gray (Gy) or $\geq 30 \mathrm{~Gy}$ [40]. Other treatment exposures related to the original cancer diagnosis were divided into any chemotherapy, anthracycline-containing cardiotoxic chemotherapy, and hematopoietic stem cell transplantation (HSCT). We also retrieved records on relapse during follow-up.

\subsubsection{Cardiovascular Risk Profiles}

We created three different cardiovascular risk profiles: (A) personal history of CVD and modifiable cardiovascular risk factors, and, specifically, (B) BMI at survey, and (C) cardiotoxic cancer treatment. We divided each risk profile into three severity levels. Personal history of CVD and modifiable cardiovascular risk factors (A) was split into: (1) "CVD" including heart attack, cardiomyopathy, angina pectoris, atrial fibrillation, arteriosclerosis, stroke, transient ischemic attack (TIA), and/or deep venous thrombosis; (2) "CVD risk factors" including hypertension (repeated high blood pressure measurements or antihypertensive medication treatment), obesity, diabetes mellitus treated with either tablets or insulin, current smoking, and/or high cholesterol defined as treatment with lipid-lowering medications, or (3) "CVD risk-free" if survivors did not report any of these conditions (Supplementary Figure S2A,B). Survivors could suffer from several CVD problems and CVD risk factors. BMI at survey (B) was categorized as (1) "Obese", (2) "Overweight", or (3) "Normal/underweight". We categorized cardiotoxic cancer treatment (C) as (1) "Both anthracyclines and chest irradiation", (2) "Either anthracyclines or chest irradiation", or (3) "Neither anthracyclines nor chest irradiation". Survivors were stratified into the three risk profiles $(\mathrm{A}, \mathrm{B}$, and $\mathrm{C})$ based on their self-reports in the survey (A and $\mathrm{B})$ or the information we extracted from the SCCR (C).

\subsubsection{Statistical Analyses}

We included all CCSs who provided reliable dietary intake information [41] and were not pregnant or lactating during the FFQ survey (Supplementary Figure S1). We compared the sociodemographic, lifestyle, and clinical characteristics of participants and nonparticipants to the SCCSS-Nutrition study. We also compared the dietary intake of participants to the FFQ and urine spot sample collection and between language regions within Switzerland. First, we assessed daily $\mathrm{Na}$ and $\mathrm{K}$ intake and determined if CCSs met the dietary DACH recommendations for $\mathrm{Na}$ and $\mathrm{K}$ intakes for Germany (D), Austria (A), and Switzerland ( $\mathrm{CH})$ [35]. To do this, we used both dietary assessment tools: the FFQ and the morning fasting spot urine. We used a Bland-Altman plot to determine the absolute agreement of $\mathrm{Na}$ and $\mathrm{K}$ intakes between the tools.

We then used analysis of covariance (ANCOVA) to assess differences in $\mathrm{Na}$ and $\mathrm{K}$ intakes (g/day) of CCSs across cardiovascular risk profiles A-C, adjusting for sex, age at survey (continuous), and ICCC-3 cancer diagnosis. We did not adjust initially for education level, smoking habits, physical activity, diet quality, or alcohol consumption because of our limited sample size and because these covariates may be affected by CVD, obesity, or cardiotoxic treatment (they are potential intermediates on the causal pathway). We tested if $\mathrm{Na}$ and $\mathrm{K}$ intake was approximately normally distributed for each category of the cardiovascular risk profile (profile A-C) by using the Shapiro-Wilk test of normality and skewness kurtosis test. To test for homoscedasticity, we used the Levene's test for homogeneity of variances. We failed to reject a normal distribution for $\mathrm{Na}$ and $\mathrm{K}$ intake. There was also no issue with homoscedasticity. To compare differences between CVD risk groups, we calculated $p$-value from 
chi-square statistics (categorical, 2-sided test), analysis of variance (ANOVA, continuous, parametric), or the Kruskal-Wallis test (continuous, nonparametric). We determined the correlation between $\mathrm{Na}$ and $\mathrm{K}$ intakes (g/day) and self-reported BMI at FFQ survey $\left(\mathrm{kg} / \mathrm{m}^{2}\right)$.

All analyses were carried out with Stata (version 14, Stata Corporation, Austin, Texas). Statistical significance tests were two-sided with a significance level of $5 \%$.

\section{Results}

Of 1749 eligible CCSs, we traced and contacted 1599, of whom 919 (57\%) returned an FFQ (Supplementary Figure S1). We excluded 11 survivors who were pregnant or breastfeeding, 35 who did not report their dietary intake, and 71 whose dietary intake data ( $<850 \mathrm{kcal}$ or $>4500 \mathrm{kcal}$ per day) was unreliable [42]. We included 802 CCSs with FFQ data and sent 212 a spot urine sample collection kit; 111 morning fasting spot urine samples (52\%) were returned to us.

Half of the CCSs were males; median age at FFQ survey was 35 years (interquartile range (IQR): 29-41 years): $21 \%$ were physically inactive, $16 \%$ smoked, and $9 \%$ were obese (Table 1 ). The mean alternative healthy eating index (AHEI) was 50.3 (95\% CI: 49.1-51.5) for males and 56.0 (54.8-57.2) for females $($ maximum score $=110)$ (Table 1, Supplementary Table S1). Based on the self-reported personal history of CVD and cardiovascular risk factors (A), the groups differed in sociodemographic and lifestyle characteristics. CCSs who had CVD or CVD risk factors were more often males, were older, were less educated, lived alone, smoked, were obese, and consumed more alcohol than those who were CVD risk-free ( $p_{\text {all }}<0.05$, Table 1 ). The most common baseline cancers in CCSs had been leukemia, lymphoma, and central nervous system (CNS) tumors (Table 2). Median age at diagnosis was ten years (IQR: 4-14 years) and the median time from diagnosis to survey was 26 years (IQR: 20-32 years). More than a third of CCSs had received anthracyclines; $11 \%$ had chest irradiation. At baseline SCCSS questionnaire, $6 \%$ of the CCSs had CVD, 23\% had CVD risk factors, and 71\% were CVD risk-free. All CCSs who had indicated to have CVD at baseline still had CVD at the time of follow-up survey. Of those 187 CCSs who had CVD risk factors at baseline, 21 (11\%) developed CVD, 118 (63\%) stayed at risk, and $48(26 \%)$ returned to CVD risk-free at follow-up. These 48 CCSs were no longer at CVD risk at follow-up survey since they had stopped smoking (90\%), were no longer obese (6\%), or had no longer hypertension (4\%). At follow-up, 14\% of the CCSs had CVD, 23\% had CVD risk factors, and $62 \%$ were CVD risk-free.

Participants who filled in an FFQ were more often females, older, more likely to be born in Switzerland, tended to have a healthier lifestyle, and were younger at diagnosis than those who did not fill in an FFQ (Supplementary Table S2 and S3). Participants who returned a spot urine sample were older so time since their diagnosis was longer, but otherwise, they were similar to those who did not return a urine sample (Supplementary Tables S2 and S3).

$\mathrm{Na}$ intake was higher than DACH recommends-when we used FFQ data it was $190 \%$ of the recommended level; it was $197 \%$ when we used spot urine samples (Table 3). Daily K intake was lower than DACH recommends - it was 68\% when we used FFQ data and $40 \%$ when we used spot urine samples. Results for the subgroup taking part in the urine study $(n=111)$ were similar to the entire population $(n=802)$ and those who filled in the FFQ but did not provide a spot urine sample $(n=691$; Supplementary Table S4). Na and K intake estimated by FFQ did not differ across language regions of Switzerland (Supplementary Table S5). Mean difference in daily Na intake, estimated by morning fasting spot urine and FFQ, was $0.2 \mathrm{~g} /$ day, and limits of agreement, of which $95 \%$ of the differences of spot urine samples compared to FFQ fall, were -1.2 and $1.5 \mathrm{~g}$ (Figure 1a). The mean difference in daily $\mathrm{K}$ intake, estimated by morning fasting spot urine and FFQ, was $-1.0 \mathrm{~g}$, and limits of agreement were -3.4 and $1.3 \mathrm{~g}$ (Figure $1 \mathrm{~b}$ ). Na intake was similar, whether based on FFQ or spot urine. K intake was lower when based on spot urine than when estimated by FFQ. 
Table 1. Sociodemographic and lifestyle characteristics of adult childhood cancer survivors (CCSs) by cardiovascular risk profile (A).

\begin{tabular}{|c|c|c|c|c|c|}
\hline & \multirow{2}{*}{$\begin{array}{c}\text { Total } \\
\begin{array}{c}\text { CCSs } \\
n=802\end{array}\end{array}$} & \multicolumn{4}{|c|}{ Cardiovascular Risk Profile Based on (A) Personal History of CVD and Modifiable Risk Factors } \\
\hline & & $\begin{array}{l}\text { CVD }^{1} \\
n=114\end{array}$ & $\begin{array}{c}\text { CVD Risk Factors }^{2} \\
n=187\end{array}$ & $\begin{array}{c}\text { CVD Risk-Free } \\
n=501\end{array}$ & \\
\hline & $n(\%)$ & $n(\%)$ & $n(\%)$ & $n(\%)$ & $p$-Value ${ }^{3}$ \\
\hline \multicolumn{6}{|l|}{ Sex } \\
\hline Females & $401(50)$ & $64(56)$ & $74(40)$ & $263(53)$ & 0.004 \\
\hline Males & $401(50)$ & $50(44)$ & $113(60)$ & $238(48)$ & \\
\hline Age at survey, median (IQR) & $34.6(28.8 ; 41.1)$ & $38.0(30.4 ; 45.2)$ & $35.3(29.5 ; 43.0)$ & $34.1(27.9 ; 39.7)$ & $<0.001$ \\
\hline$\leq 30 \mathrm{y}$ & $248(31)$ & $28(25)$ & $54(29)$ & $166(33)$ & $<0.001$ \\
\hline $31-39$ y & $320(40)$ & $38(33)$ & $66(35)$ & $216(43)$ & \\
\hline$\geq 40 \mathrm{y}$ & $234(29)$ & $48(42)$ & $67(36)$ & $119(24)$ & \\
\hline \multicolumn{6}{|l|}{ Country of birth } \\
\hline Switzerland & $763(95)$ & $111(97)$ & $173(93)$ & $479(96)$ & 0.119 \\
\hline Other & $39(5)$ & $3(3)$ & $14(7)$ & $22(4)$ & \\
\hline \multicolumn{6}{|l|}{ Language region within Switzerland } \\
\hline German speaking & $570(71)$ & $82(72)$ & $123(66)$ & $365(73)$ & 0.480 \\
\hline French speaking & $214(27)$ & $30(26)$ & $59(32)$ & $125(25)$ & \\
\hline Italian speaking & $18(2)$ & $2(2)$ & $5(3)$ & $11(2)$ & \\
\hline \multicolumn{6}{|l|}{ Education (highest degree) } \\
\hline Lower than university & $532(66)$ & $77(68)$ & $142(76)$ & $313(62)$ & 0.004 \\
\hline University & $270(34)$ & $37(32)$ & $45(24)$ & $188(38)$ & \\
\hline \multicolumn{6}{|l|}{ Living situation } \\
\hline Alone & $164(20)$ & $24(21)$ & $52(28)$ & $88(18)$ & 0.012 \\
\hline With others & $638(80)$ & $90(79)$ & $135(72)$ & $413(82)$ & \\
\hline \multicolumn{6}{|l|}{ Physical activity 4} \\
\hline Inactive & $165(21)$ & $26(23)$ & $39(21)$ & $100(20)$ & 0.790 \\
\hline Active & $637(79)$ & $88(77)$ & $148(79)$ & $401(80)$ & \\
\hline \multicolumn{6}{|l|}{ Smoking status } \\
\hline Current & $128(16)$ & $15(13)$ & $113(60)$ & - & $<0.001$ \\
\hline Former & $132(16)$ & $24(21)$ & $11(6)$ & $97(19)$ & \\
\hline & $542(68)$ & $75(66)$ & $63(34)$ & $404(81)$ & \\
\hline \multicolumn{6}{|l|}{ BMI at survey } \\
\hline Obese, $\geq 30 \mathrm{~kg} / \mathrm{m}^{2}$ & $75(9)$ & $13(11)$ & $62(33)$ & - & $<0.001$ \\
\hline Overweight, $\geq 25$ to $<30 \mathrm{~kg} / \mathrm{m}^{2}$ & $177(22)$ & $26(23)$ & $43(23)$ & $108(22)$ & \\
\hline Normal, $\geq 18.5$ to $<25 \mathrm{~kg} / \mathrm{m}^{2}$ & $511(64)$ & $72(63)$ & $76(41)$ & $363(72)$ & \\
\hline Underweight, $<18.5 \mathrm{~kg} / \mathrm{m}^{2}$ & $39(5)$ & $3(3)$ & $6(3)$ & $30(6)$ & \\
\hline $\mathrm{AHEI}^{5}$, mean $\pm \mathrm{SD}$ & $53.1 \pm 12.7$ & $53.7 \pm 10.8$ & $51.3 \pm 12.4$ & $53.7 \pm 13.1$ & 0.089 \\
\hline Alcohol ${ }^{6}$, mean drinks/day $\pm \mathrm{SD}$ & $0.43 \pm 0.61$ & $0.36 \pm 0.50$ & $0.58 \pm 0.75$ & $0.39 \pm 0.56$ & $<0.001$ \\
\hline
\end{tabular}

AHEI —alternative healthy eating index; BMI—body mass index; CCSs—childhood cancer survivors; IQR —interquartile range; SD—standard deviation. ${ }^{1}$ This includes 69 CCSs with atrial fibrillation, 21 with deep venous thrombosis, 20 with cardiomyopathy, 10 with stroke/ transient ischemic attack (TIA), 8 with angina pectoris, 5 with a heart attack, and 5 with arteriosclerosis. ${ }^{2}$ This includes 128 CCSs who are current smokers, 75 with obesity, 21 with repeated high blood pressure, 13 with high cholesterol, and 8 with diabetes mellitus treated with either tablets or insulin. ${ }^{3} p$-value calculated from chi-square statistics (categorical, 2-sided test), analysis of variance (ANOVA, continuous, parametric) or the Kruskal-Wallis test (continuous, nonparametric) to compare differences between CVD risk groups. 4 Active: $\geq 150 \mathrm{~min}$ of moderate intense or 75 min of vigorous intense or a combination of moderate and vigorous intense physical activity per week. ${ }^{5}$ Adapted from Chiuve et al. J Nutr 2012 142(6):1009-18. Adjusted for age at survey and cancer diagnosis based on the International Childhood Cancer Classification, 3rd edition. For more information see [32]. ${ }^{6}$ One serving was $113.4 \mathrm{~g}$ of wine, $340.2 \mathrm{~g}$ of beer or $42.5 \mathrm{~g}$ of liquor. 
Table 2. Clinical characteristics of adult childhood cancer survivors (CCSs) by cardiovascular risk profile (A).

\begin{tabular}{|c|c|c|c|c|c|}
\hline & \multirow{2}{*}{$\begin{array}{c}\text { Total } \\
\text { CCSs } \\
n=802\end{array}$} & \multicolumn{4}{|c|}{ Cardiovascular Risk Profile Based on (A) Personal History of CVD and Modifiable Risk Factors } \\
\hline & & $\begin{array}{l}\text { CVD }^{2} \\
n=114\end{array}$ & $\begin{array}{c}\text { CVD Risk Factors }^{3} \\
n=187\end{array}$ & $\begin{array}{c}\text { CVD Risk-Free } \\
n=501\end{array}$ & \\
\hline & $n(\%)$ & $n(\%)$ & $n(\%)$ & $n(\%)$ & $p$-value ${ }^{4}$ \\
\hline \multicolumn{6}{|l|}{ ICCC 3 diagnosis } \\
\hline I: Leukemia & $246(31)$ & $35(31)$ & $55(29)$ & $156(31)$ & 0.189 \\
\hline II: Lymphoma & $173(22)$ & $25(22)$ & $42(22)$ & $106(21)$ & \\
\hline III: CNS tumor & $81(10)$ & $7(6)$ & $28(15)$ & $46(9)$ & \\
\hline IV: Neuroblastoma & $28(3)$ & $5(4)$ & $6(3)$ & $17(3)$ & \\
\hline V: Retinoblastoma & $12(2)$ & - & $4(2)$ & $8(2)$ & \\
\hline VI: Renal tumor & $52(6)$ & $7(6)$ & $8(4)$ & $37(7)$ & \\
\hline VII: Hepatic tumor & $6(<1)$ & $3(3)$ & $1(<1)$ & $2(<1)$ & \\
\hline VIII: Bone tumor & $50(6)$ & $7(6)$ & $10(5)$ & $33(7)$ & \\
\hline IX: Soft tissue sarcoma & $66(8)$ & $13(11)$ & $8(4)$ & $45(9)$ & \\
\hline X: Germ cell tumor & $43(5)$ & $8(7)$ & $10(5)$ & $25(5)$ & \\
\hline XI \& XII: Other tumors & $26(3)$ & $3(3)$ & $9(5)$ & $14(3)$ & \\
\hline Langerhans cell histiocytosis & $19(2)$ & $1(<1)$ & $6(3)$ & $12(2)$ & \\
\hline Age at diagnosis ${ }^{1}$ years & $9.7(3.9 ; 13.9)$ & $10.8(5.1 ; 15.5)$ & $10.3(4.0 ; 13.8)$ & $8.8(3.8 ; 13.7)$ & 0.232 \\
\hline Time since diagnosis ${ }^{1}$ years & $26.1(20.2 ; 31.7)$ & $28.5(21.3 ; 34.7)$ & $26.5(20.8 ; 32.3)$ & $25.3(19.8 ; 30.7)$ & 0.002 \\
\hline Irradiation, any & $292(36)$ & $46(40)$ & $64(34)$ & $182(36)$ & 0.562 \\
\hline Chest irradiation & $87(11)$ & $14(12)$ & $14(7)$ & $59(12)$ & 0.238 \\
\hline$<30$ Gy & $31(4)$ & $6(5)$ & $4(2)$ & $21(4)$ & 0.486 \\
\hline$\geq 30$ Gy & $56(7)$ & $8(7)$ & $10(5)$ & $38(8)$ & \\
\hline Any chemotherapy & $642(80)$ & $98(86)$ & $142(76)$ & $402(80)$ & 0.106 \\
\hline Anthracyclines & $298(37)$ & $46(40)$ & $61(33)$ & $191(38)$ & 0.309 \\
\hline HSCT & $30(4)$ & $6(5)$ & $6(3)$ & $18(4)$ & 0.634 \\
\hline History of relapse & $99(12)$ & $16(14)$ & $23(12)$ & $60(12)$ & 0.833 \\
\hline
\end{tabular}

CCSs—childhood cancer survivor; CNS—central nervous system; CVD—cardiovascular disease; Gy—gray; HSCT—hematopoietic stem cell transplantation; ICCC-3-International Childhood Cancer Classification, 3rd edition, IQR - interquartile rang; NA—not applicable ${ }^{1}$ Values are medians (IQRs). ${ }^{2}$ This includes 69 CCSs with atrial fibrillation, 21 with deep venous thrombosis, 20 with cardiomyopathy, 10 with stroke/ transient ischemic attack (TIA), 8 with angina pectoris, 5 with a heart attack, and 5 with arteriosclerosis. ${ }^{3}$ This includes 128 CCSs who are a current smoker, 75 with obesity, 21 with repeated high blood pressure, 13 with high cholesterol, and 8 with diabetes mellitus treated with either tablets or insulin. ${ }^{4} p$-value calculated from chi-square statistics (categorical, 2-sided test) or the Kruskal-Wallis test (continuous, nonparametric) to compare differences between CVD risk groups. 
Table 3. Sodium (Na) and potassium (K) intake of adult childhood cancer survivors (CCSs).

\begin{tabular}{|c|c|c|c|c|c|}
\hline & \multirow{3}{*}{$\begin{array}{c}\text { DACH } \\
\text { Recommendations }\end{array}$} & \multicolumn{4}{|c|}{ CCSs } \\
\hline & & \multicolumn{2}{|c|}{$\begin{array}{c}\text { Based on FFQ } \\
\quad n=802\end{array}$} & \multicolumn{2}{|c|}{$\begin{array}{c}\text { Based on Morning Fasting } \\
\text { Spot Urine } \\
n=111\end{array}$} \\
\hline & & Mean \pm SD & $\%$ DACH $^{3}$ & Mean \pm SD & $\% \mathrm{DACH}^{3}$ \\
\hline $\mathrm{Na}, \mathrm{g}$ & 1.5 & $2.8 \pm 0.7^{2}$ & 190 & $2.9 \pm 0.8^{4}$ & 197 \\
\hline $\mathrm{K}, \mathrm{g}$ & 4.0 & $2.7 \pm 1.1$ & 68 & $1.6 \pm 1.0^{5}$ & 40 \\
\hline $\mathrm{Na}: \mathrm{K}$ ratio 6 & - & $1.2 \pm 0.5$ & - & $2.3 \pm 1.0$ & - \\
\hline $\mathrm{Na}$ :Cre ratio & - & - & & $2.3 \pm 0.4^{7}$ & - \\
\hline $\mathrm{K}:$ Cre ratio & - & - & & $1.2 \pm 0.7^{7}$ & - \\
\hline
\end{tabular}

CCS—childhood cancer survivors, Cre-creatinine; DACH—dietary recommendations for Germany (D), Austria (A) and Switzerland (CH); Na-sodium; $\mathrm{K}$ - potassium. ${ }^{1}$ DACH recommendations for the general population age 20-50 years, excluding pregnant and lactating females, 2015. Recommendations for $\mathrm{Na}$ and $\mathrm{K}$ are similar for males and females [35].

${ }^{2} \mathrm{Na}$ intake based on FFQ data was calculated with the equation: $(8.20+0.38 \times$ FFQ in males) $/ 2.54$ and $(4.55+0.67 \times$ FFQ in females)/2.54, with $1 \mathrm{~g} \mathrm{Na}=2.54 \mathrm{~g}$ salt $(\mathrm{NaCl})$ see [25]. Intake based on FFQ data only gives a mean daily intake of $1.9 \mathrm{~g} \pm 0.8 .{ }^{3}$ Percentage of mean intake in relation to the DACH recommended intake level $\times 100$. Recommended intake is estimated on the basis of the age-sex groups of the DACH guidelines, weighted by the age and sex distribution of the study population [35]. ${ }^{4}$ Calculated based on the International Cooperative Study on Salt, Other Factors, and Blood Pressure (INTERSALT) equation [36]. ${ }^{5}$ Calculated based on the combined Pan American Health Organization (PAHO)/Chronic Kidney Disease Epidemiology Collaboration (CKD-EPI) equation [10,37]. ${ }^{6} \mathrm{Na}: \mathrm{K}$ ratio, as an indicator for CVD risk, was calculated by dividing estimated Na intake (g/day) by estimated $\mathrm{K}$ intake (g/day). A high Na:K ratio is associated with an increased risk of CVD. ${ }^{7} \mathrm{Na} / \mathrm{K}$ : Cre ratio was calculated using the INTERSALT, the combined PAHO/CKD-EPI, and CKD-EPI equation $[10,36,37]$.

$\mathrm{Na}$ and $\mathrm{K}$ intakes did not differ between childhood cancer survivors across CVD risk profiles based on FFQ data (Table 4). Those with CVD risk factors had a slightly higher Na intake ( $3.3 \mathrm{~g} /$ day) calculated from morning fasting spot urine than those who were CVD risk-free ( $2.9 \mathrm{~g} /$ day) or those with $\operatorname{CVD}(2.7 \mathrm{~g} /$ day, $p=0.017, \mathrm{~A})$; these results are in large part driven by obesity. Obese $(4.2 \mathrm{~g} /$ day $)$ or overweight ( $3.3 \mathrm{~g} /$ day) participants had a higher $\mathrm{Na}$ intake based on morning fasting spot urine than those who were normal/underweight $(2.7 \mathrm{~g} / \mathrm{day}, p<0.001$, B). Na intake estimated from spot urine was positively correlated with BMI $(r=0.57$, Figure $2 a)$. This was not seen for estimates based on FFQ $(r=0.16)$. We saw no relationship between $\mathrm{K}$ intake and BMI at the time of the survey, whether based on FFQ or spot urine (Figure 2b). We found no association of $\mathrm{Na}$ intake with cardiotoxic treatment groups (C), whether based on FFQ or spot urine data. The same was true for K. Additional adjustment for BMI at survey did not change our results for cardiotoxic treatment groups. Our results for $\mathrm{Na}$ and $\mathrm{K}$ intake across CVD risk profiles (A-C) did not change after additional adjustment for education level, smoking habits, physical activity, diet quality, or alcohol consumption. 
Table 4. Mean sodium (Na) and potassium (K) intake (g/day) in childhood cancer survivors by cardiovascular risk profiles (A-C), retrieved from ANCOVA 1.

\begin{tabular}{|c|c|c|c|c|c|c|c|c|c|c|}
\hline & \multicolumn{5}{|c|}{$\begin{array}{l}\text { Based on FFQ } \\
\quad n=802\end{array}$} & \multicolumn{5}{|c|}{$\begin{array}{l}\text { Based on Morning Fasting Spot Urine } \\
\qquad n=111\end{array}$} \\
\hline & $n(\%)$ & $\mathrm{Na}^{2}(95 \% \mathrm{CI})$ & $p$ & $\mathrm{~K}(95 \% \mathrm{CI})$ & $p$ & $n(\%)$ & $\mathrm{Na}(95 \% \mathrm{CI})$ & $p$ & $\mathrm{~K}(95 \% \mathrm{CI})$ & $p$ \\
\hline \multicolumn{11}{|l|}{ Cardiovascular risk profile } \\
\hline \multicolumn{11}{|l|}{ (A) Personal history of CVD and risk factors } \\
\hline CVD & $114(14)$ & $2.9(2.8,2.9)$ & 0.538 & $2.7(2.5,2.9)$ & 0.058 & $16(14)$ & $2.7(2.3,3.0)$ & 0.017 & $1.3(0.8,1.8)$ & 0.490 \\
\hline CVD risk factors & $187(23)$ & $2.8(2.8,2.9)$ & & $2.6(2.4,2.7)$ & & $28(25)$ & $3.3(3.0,3.6)$ & & $1.7(1.3,2.1)$ & \\
\hline CVD risk-free & $501(62)$ & $2.8(2.8,2.9)$ & & $2.8(2.7,2.9)$ & & $67(60)$ & $2.9(2.7,3.0)$ & & $1.6(1.4,1.8)$ & \\
\hline \multicolumn{11}{|l|}{ (B) Self-reported BMI at survey } \\
\hline Overweight, $\geq 25$ to $<30 \mathrm{~kg} / \mathrm{m}^{2}$ & $177(22)$ & $2.9(2.8,2.9)$ & & $2.8(2.6,2.9)$ & & $15(14)$ & $3.3(3.0,3.6)$ & & $1.6(1.1,2.1)$ & \\
\hline $\begin{array}{l}\text { Normal/underweight, }<25 \mathrm{~kg} / \mathrm{m}^{2} \\
\text { (C) Cardiotoxic treatment }\end{array}$ & $550(69)$ & $2.8(2.8,2.9)$ & & $2.8(2.7,2.9)$ & & $86(77)$ & $2.7(2.6,2.9)$ & & $1.5(1.3,1.7)$ & \\
\hline Both anthracyclines and chest irradiation & $51(6)$ & $2.9(2.8,2.9)$ & 0.481 & $3.1(2.7,3.4)$ & 0.082 & $9(8)$ & $3.3(2.8,3.9)$ & 0.349 & $1.8(1.1,2.5)$ & 0.518 \\
\hline Either anthracyclines or chest irradiation & $283(35)$ & $2.8(2.8,2.9)$ & & $2.8(2.6,2.9)$ & & $36(32)$ & $3.0(2.7,3.2)$ & & $1.7(1.4,2.1)$ & \\
\hline Neither anthracyclines nor chest irradiation & $468(58)$ & $2.8(2.8,2.9)$ & & $2.7(2.6,2.8)$ & & $66(59)$ & $2.9(2.7,3.1)$ & & $1.5(1.2,1.7)$ & \\
\hline
\end{tabular}

ANCOVA—analysis of covariance; BMI—body mass index; CVD—cardiovascular disease; FFQ—food frequency questionnaire; $\mathrm{K}$-potassium; Na—sodium. ${ }^{1}$ Adjusted for sex, age at survey, and ICCC-3 cancer diagnosis. ${ }^{2} \mathrm{Na}$ intake based on FFQ data was calculated with the equation: $(8.20+0.38 \times \mathrm{FFQ}$ in males)/2.54 and $(4.55+0.67 \times \mathrm{FFQ}$ in females $) / 2.54$, with $1 \mathrm{~g}$

$\mathrm{Na}=2.54 \mathrm{~g}$ salt $(\mathrm{NaCl})$ see [25]. Intake based on FFQ data only gives a mean daily intake of $1.9 \mathrm{~g} \pm 0.8$. 

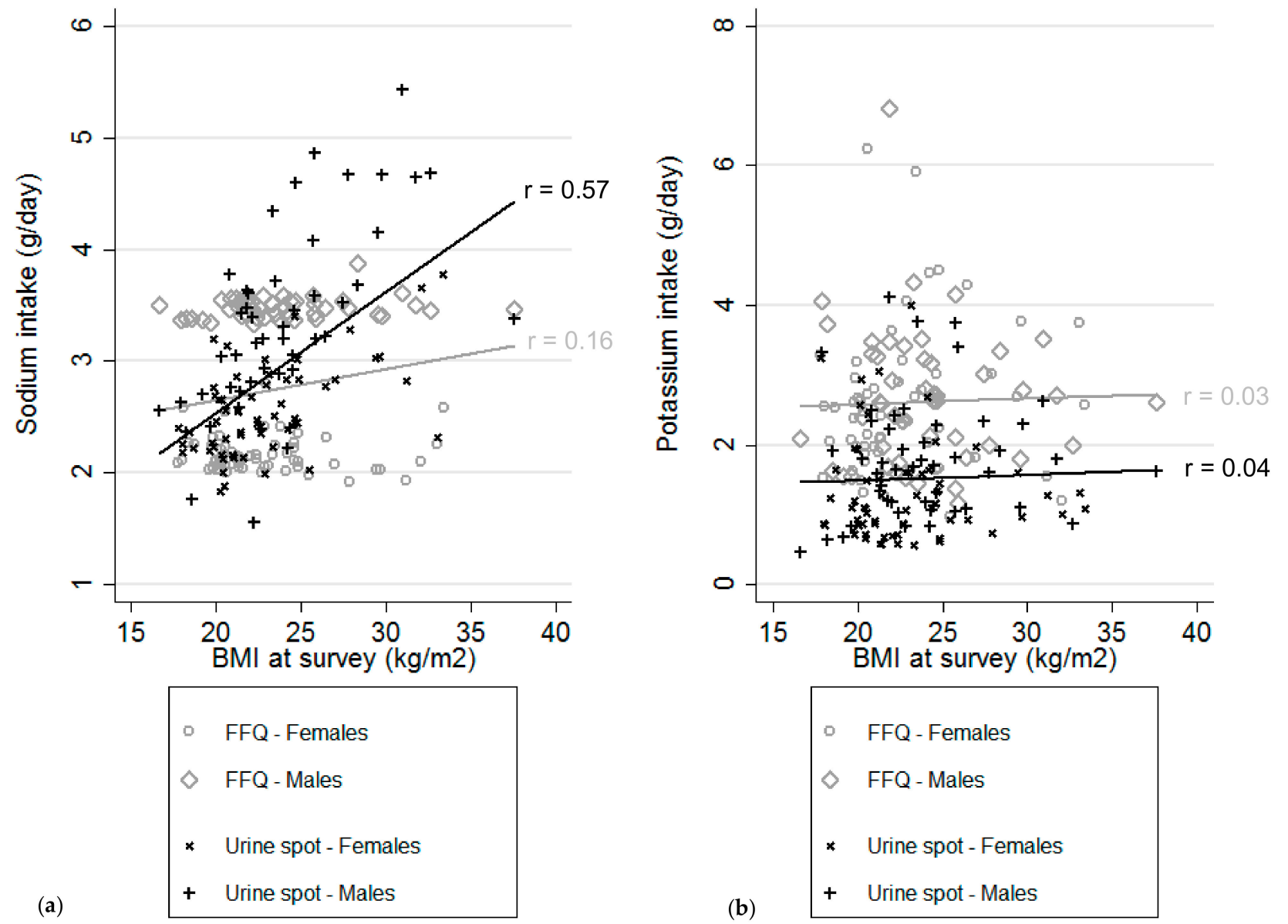

Figure 2. Cardiovascular risk profile B - correlation between BMI and sodium ${ }^{1}$ (a) and potassium (b) measurements by food frequency questionnaire (FFQ) and morning fasting spot urine samples. BMI—body mass index; FFQ—food frequency questionnaire. ${ }^{1}$ Sodium (Na) intake based on FFQ data was calculated with the equation: $(8.20+0.38 \times \mathrm{FFQ}$ in males) $/ 2.54$ and $(4.55+0.67 \times \mathrm{FFQ}$ in females)/2.54, with $1 \mathrm{~g} \mathrm{Na}=2.54 \mathrm{~g}$ salt $(\mathrm{NaCl})$ see [25]. Intake based on FFQ data only gives a mean daily intake of $1.9 \mathrm{~g} \pm 0.8$. 


\section{Discussion}

\subsection{Principal Findings}

$\mathrm{Na}$ and $\mathrm{K}$ intakes did not meet dietary recommendations among CCSs at a median of 26 years after participants' cancer diagnosis. Na intake was almost double the recommended amount and $\mathrm{K}$ intake was about half the recommended amount. Na intake was particularly high in CCSs with CVD risk factors, and those who were overweight or obese. We saw no differences between cardiotoxic cancer treatment groups.

\subsection{Strengths and Limitations}

We used an FFQ that was not specifically designed to assess $\mathrm{Na}$ and $\mathrm{K}$ intakes, so we may have under- or overestimated dietary intake. To compensate for incorrect estimated daily dietary $\mathrm{Na}$ intake, we used a calibrated equation based on a validation study with 24-hour urine collection among Swiss adults [25]. After comparing the estimated Na intake assessed with FFQs using this equation and spot urine samples, we saw almost similar intake levels. To estimate Na intake from spot urine, we used the INTERSALT equation that includes urinary Cre to account for different levels of urine concentrations [36]. We took spot urine as a proxy of $24 \mathrm{~h}$ urine. The observed difference between K intake estimated from FFQ (2.7 g/day) and spot urine samples (1.6 g/day) could be due to over-reporting of fruit and vegetable consumption in the FFQ, the mean $196 \pm 40$ days between our two assessments [24], or diurnal variation of urinary K excretion. We asked CCSs for a single spot urine sample rather than multiple spot samples or 24-hour urine collections to minimize participation burden, although this is not considered the most accurate method to estimate daily Na intake. The collection of 24-hour urine is burdensome for CCSs, with a risk of incomplete collection and low response rates. Estimating $\mathrm{Na}$ and $\mathrm{K}$ excretions from morning fasting urine spots are a simple and cheap alternative, potential under- or over-collection is irrelevant and is considered to correlate well with 24-hour urine collections [43]. Yet, a single spot urine does not adequately capture intra-individual daily variations in $\mathrm{Na}$ and $\mathrm{K}$ intakes. Second, our data were based on a cross-sectional analysis, so that the captured dietary intakes represent current intakes and not past intakes. Dietary intake of CCSs with CVD or those with CVD risk factors could have changed over time due to, e.g., dietary recommendations from health care professionals, aging. We saw that survivors with CVD had a lower Na intake but a similar $\mathrm{K}$ intake, than those with CVD risk factors or who were CVD risk-free, suggesting that CCSs with CVD made salt reducing adaptations to their diet. However, only a few CCSs explicitly said that they followed a diet regimen because of an earlier CVD event. When looking at overall diet quality assessed with the AHEI, we saw similar scores between CCSs with CVD and those risk-free, whereas those with CVD risk factors scored slightly lower reflecting a poorer diet quality. Finally, all cardiac events as well as modifiable CVD risk factors were self-reported without medical record confirmation which could have led to incorrect reports. To improve validity, we went through the list of self-reported described medications to check if they were taken for antihypertensive, diabetes, and lipid-lowering medication treatment. CCSs were asked to report all their prescribed medication at the time of the FFQ survey.

Despite these limitations, the SCCSS-Nutrition study is strengthened by the large number of respondents who returned their FFQ and spot urine samples and our relatively long follow-up time after diagnosis. The SCCSS is strengthened by its national coverage, large sample size, and high response rate, which makes our results reasonably representative of this group nationwide. Furthermore, we had access to high-quality clinical information on cancer diagnosis and treatment extracted from the SCCR.

\subsection{Na and K Intake and Cardiovascular disease (CVD): Results in Relation to Other Studies}

CCSs [44-49] and the general population [15,25] often do not adhere to national or international dietary $\mathrm{Na}$ and $\mathrm{K}$ recommendations, so our finding is in line with those other studies. Our study showed a Na intake above dietary recommendations (males: $3.5 \mathrm{~g} /$ day, females: $2.2 \mathrm{~g} /$ day; 21-59 years), but a lower intake compared to the general Swiss population (males: $4.2 \mathrm{~g} / \mathrm{day}$, females: $3.2 \mathrm{~g} / \mathrm{day}$; 
35-74 years) [25]. This difference may be due to the dissimilarity in age, as energy-adjusted salt intakes increases with age [25]. Excessive $\mathrm{Na}$ (143-155\% the recommended level) and too low $\mathrm{K}$ (50-58\% the recommended level) intakes were also observed in American CCSs [45,46]. Previous studies assessed $\mathrm{Na}$ and $\mathrm{K}$ intake based on FFQ data [45,47,49], 3-day food records [44,48], or 24-hour recalls [46]. These assessment methods have their limitations, e.g., underestimation of intake, recall bias [50], and may be subject to variability. Variability between methods may be due to the in- or exclusion of discretionary salt usage assessment like salt or salt-containing condiments added during cooking or the amount of food items questioned. Multiple 24-hour or spot urine collections could give us a better picture of real $\mathrm{Na}$ and $\mathrm{K}$ intake in this population. We found that CCSs who were overweight or obese had a higher estimated Na intake than normal/underweight CCSs, as in the general population [19]. The observed higher Na intake in obese CCSs might be associated with higher energy intake, fat metabolism, or insulin resistance $[19,51]$.

There is strong evidence that reducing Na intake lowers blood pressure and hypertension risk [11]. Blood pressure response to $\mathrm{Na}$ intake is greater in children, adolescents, and adults with hypertension than in those without $[15,52]$, so reducing Na intake in all CCSs, especially those who suffer from hypertension, could lower blood pressure and eventually reduce cardiovascular events and mortality. Because there were relatively few CCSs with hypertension in our sample $(n=21)$, we did not compare $\mathrm{Na}$ intake between CCSs with and those without hypertension; initially, we saw no significant differences in $\mathrm{Na}$ intake between these groups. Although optimal daily $\mathrm{Na}$ and $\mathrm{K}$ intake levels are still debated, moderate $\mathrm{Na}$ intake and high $\mathrm{K}$ intake appeared to be associated with the lowest risk of developing cardiovascular events and mortality in a study that included 103,570 participants from around the world [15]. Survivors might particularly benefit from dietary counseling, since they have an increased risk of developing CVD due to cardiotoxic cancer treatment [6,7]. Further research is needed to determine whether dietary intervention reduces cardiovascular events in CCSs at risk of developing CVD and if there are differences between those with and without hypertension.

\subsection{Implications and Recommendations}

Pediatric oncology centers and follow-up clinics for CCSs in Switzerland follow the COG-LTFU guidelines, which advises a healthy lifestyle and medical management of modifiable cardiovascular risk factors in survivors at risk of CVD [53]. These guidelines include recommendations to consume a heart-healthy diet with avoidance of high salt intake [54]. Adherence to these guidelines may explain the lower daily Na intake observed in CCSs with CVD than in those who are CVD risk-free. Counseling survivors at risk of developing CVD to reduce their $\mathrm{Na}$ intake and increase their $\mathrm{K}$ intake may be an important intervention. Doctors should be supported by dieticians to improve other modifiable cardiovascular risk factors in CCSs such as overweight/obesity and dyslipidemia. Health care professionals and CCSs should be more aware about the increased CVD risk of CCSs to enhance CVD surveillance, early detection of asymptomatic CVD, routine screening and appropriate management of modifiable CVD risk factors, and to support diet and lifestyle modifications in an earlier stage to reduce CVD risk. Since CCSs have similar Na and K intakes as the general Swiss population, structural preventive measures are important as well. A first step could be population-based interventions promoting increased intake of potassium-containing foods, e.g., fruit, vegetables, nuts, discouraging the intake of salty foods and snacks, and reducing the salt content of processed and prepared foods by cooperating with the food industry.

\section{Conclusions}

We found poor dietary Na and K intakes in CCSs long after cancer diagnosis in Switzerland. High sodium intake was particular marked in those with CVD risk factors, or who were overweight or obese. Adult survivors of childhood cancer need dietary assistance to reduce $\mathrm{Na}$ and increase $\mathrm{K}$ intake. How this might specifically be done should be informed by further research into how CCSs may have acquired particular, post-treatment dietary tastes and habits. 
Supplementary Materials: The following are available online at http://www.mdpi.com/2072-6643/12/1/57/s1, Table S1: Scoring method and mean scores (95\% CI) of components of the modified Alternate Healthy Eating Index 1,2 of adult childhood cancer survivors (CCSs) who filled in the food frequency questionnaire by sex, Table S2: Sociodemographic and lifestyle characteristics of adult childhood cancer survivors by participants and nonparticipants to the SCCSS-Nutrition study, Table S3: Clinical characteristics of adult childhood cancer survivors by participants and nonparticipants to the SCCSS-Nutrition study, Table S4: Dietary intake based on self-reported food frequency questionnaire (FFQ) data of adult childhood cancer survivors by participants to the SCCSS-Nutrition study, Table S5: Sodium (Na) and potassium $(\mathrm{K})$ intake based on food frequency questionnaire (FFQ) data of adult childhood cancer survivors (CCSs) by language region within Switzerland, Figure S1: Response rates in the Swiss Childhood Cancer Survivor Study (SCCSS)-Nutrition study, Figure 2A.: Self-reported cardiovascular related medical history questions in French assessed within the Swiss Childhood Cancer Survivor Study(SCCSS)-Nutrition Study, Figure 2B: Self-reported cardiovascular related medical history questions in German assessed within the Swiss Childhood Cancer Survivor Study (SCCSS)-Nutrition Study.

Author Contributions: Formal Analysis, F.N.B. and M.B.; writing-original draft preparation, F.N.B.; writing-review \& editing, all authors; project conduct, M.A., M.B.P., M.B., I.G., C.E.K. All authors have read and agreed to the published version of the manuscript.

Funding: This study is supported by Swiss Cancer Research (KFS-4722-02-2019 and KLS-3886-02-2016). The work of the Swiss Childhood Cancer Registry is supported by the Swiss Pediatric Oncology Group, Schweizerische Konferenz der kantonalen Gesundheitsdirektorinnen und -direktoren, Swiss Cancer Research, Kinderkrebshilfe Schweiz, the Swiss Federal Office of Public Health, and the National Institute for Cancer Epidemiology and Registration.

Acknowledgments: The authors express their gratitude to all childhood cancer survivors for supporting this study. Additionally, we thank Sarah Blanc, Eléna Lemmel, Rosa-Emma Garcia, Rodolfo Lo Piccolo, Sandrine Estoppey-Younes, and the medical staff of CHUV for their support in study set-up, recruitment, and urine collection. We thank the Swiss Federal Food Safety and Veterinary Office (FSVO), for providing the Swiss National Nutrition Survey menuCH 2014-2015, Version 2.0 dataset (May 2017). We thank the study team of the Swiss Childhood Cancer Survivor Study (Nadine Lötscher, Maria Otth, and Nicolas Waespe), the other data managers of the Swiss Pediatric Oncology Group (Claudia Althaus, Nadine Assbichler, Pamela Balestra, Heike Baumeler, Nadine Beusch, Pierluigi Brazzola, Susann Drerup, Janine Garibay, Franziska Hochreutener, Monika Imbach, Friedgard Julmy, Heike Markiewicz, Veneranda Mattielo, Annette Reinberg, Renate Siegenthaler, Astrid Schiltknecht, Beate Schwenke, and Verena Stahel), and the team of the Swiss Childhood Cancer Registry (Meltem Altun, Erika Brantschen, Katharina Flandera, Elisabeth Kiraly, Verena Pfeiffer, Shelagh Redmond, Julia Ruppel, and Ursina Roder). Finally, we would like to thank Kali Tali and Christopher Ritter for editorial assistance.

Conflicts of Interest: The authors declare no conflict of interest.

\section{Abbreviations}

$\begin{array}{ll}\text { AHEI } & \text { Alternative Healthy Eating Index } \\ \text { ALL } & \text { Acute Lymphoblastic Leukemia } \\ \text { ANOVA } & \text { Analysis of Variance } \\ \text { ANCOVA } & \text { Analysis of Covariance } \\ \text { BMI } & \text { Body Mass Index } \\ \text { CCSs } & \text { Childhood Cancer Survivors } \\ \text { CI } & \text { Confidence Interval } \\ \text { CIQUAL } & \text { Centre d'Information sur la Qualité des Aliments } \\ \text { CKD-EPI } & \text { Chronic Kidney Disease Epidemiology Collaboration } \\ \text { CNS } & \text { Central Nervous System } \\ \text { COG-LTFU } & \text { Children's Oncology Group Long-Term Follow-up } \\ \text { Cre } & \text { Creatinine } \\ \text { DACH } & \text { Germany (D), Austria (A), and Switzerland (CH) } \\ \text { CVD } & \text { Cardiovascular Disease } \\ \text { FFQ } & \text { Food Frequency Questionnaire } \\ \text { Gy } & \text { Gray } \\ \text { HSCT } & \text { Hematopoietic Stem Cell Transplantation } \\ \text { ICCC-3 } & \text { International Classification of Childhood Cancer, 3rd edition } \\ \text { INTERSALT } & \text { International Cooperative Study on Salt, Other Factors, and Blood Pressure } \\ \text { IQR } & \text { Interquartile Range } \\ \text { K } & \text { Potassium }\end{array}$




$\begin{array}{ll}\mathrm{Na} & \text { Sodium } \\ \mathrm{NaCl} & \text { Sodium Chloride, Salt } \\ \text { PAHO } & \text { Pan American Health Organization } \\ \text { SCCR } & \text { Swiss Childhood Cancer Registry } \\ \text { SCCSS } & \text { Swiss Childhood Cancer Survivor Study } \\ \text { Sp } & \text { morning fasting spot sample } \\ \text { SPOG } & \text { Swiss Pediatric Oncology Group } \\ \text { TIA } & \text { transient ischemic attack } \\ \text { WHO } & \text { World Health Organization }\end{array}$

\section{References}

1. Scholz-Kreisel, P.; Spix, C.; Blettner, M.; Eckerle, S.; Faber, J.; Wild, P.; Merzenich, H.; Hennewig, U. Prevalence of cardiovascular late sequelae in long-term survivors of childhood cancer: A systematic review and meta-analysis. Pediatr. Blood Cancer 2017, 64, e26428. [CrossRef] [PubMed]

2. Schindler, M.; Spycher, B.D.; Ammann, R.A.; Ansari, M.; Michel, G.; Kuehni, C.E.; Swiss Paediatric Oncology, G. Cause-specific long-term mortality in survivors of childhood cancer in switzerland: A population-based study. Int. J. Cancer 2016, 139, 322-333. [CrossRef] [PubMed]

3. Armstrong, G.T.; Chen, Y.; Yasui, Y.; Leisenring, W.; Gibson, T.M.; Mertens, A.C.; Stovall, M.; Oeffinger, K.C.; Bhatia, S.; Krull, K.R.; et al. Reduction in late mortality among 5-year survivors of childhood cancer. N. Engl. J. Med. 2016, 374, 833-842. [CrossRef] [PubMed]

4. Faber, J.; Wingerter, A.; Neu, M.A.; Henninger, N.; Eckerle, S.; Münzel, T.; Lackner, K.J.; Beutel, M.E.; Blettner, M.; Rathmann, W.; et al. Burden of cardiovascular risk factors and cardiovascular disease in childhood cancer survivors: Data from the german cvss-study. Eur. Heart J. 2018, 39, 1555-1562. [CrossRef] [PubMed]

5. Armstrong, G.T.; Liu, Q.; Yasui, Y.; Neglia, J.P.; Leisenring, W.; Robison, L.L.; Mertens, A.C. Late mortality among 5-year survivors of childhood cancer: A summary from the childhood cancer survivor study. J. Clin. Oncol. 2009, 27, 2328-2338. [CrossRef] [PubMed]

6. Armenian, S.H.; Armstrong, G.T.; Aune, G.; Chow, E.J.; Ehrhardt, M.J.; Ky, B.; Moslehi, J.; Mulrooney, D.A.; Nathan, P.C.; Ryan, T.D.; et al. Cardiovascular disease in survivors of childhood cancer: Insights into epidemiology, pathophysiology, and prevention. J. Clin. Oncol. 2018, 36, 2135-2144. [CrossRef] [PubMed]

7. Armenian, S.H.; Hudson, M.M.; Mulder, R.L.; Chen, M.H.; Constine, L.S.; Dwyer, M.; Nathan, P.C.; Tissing, W.J.E.; Shankar, S.; Sieswerda, E.; et al. Recommendations for cardiomyopathy surveillance for survivors of childhood cancer: A report from the international late effects of childhood cancer guideline harmonization group. Lancet Oncol. 2015, 16, e123-e136. [CrossRef]

8. Van der Pal, H.J.; van Dalen, E.C.; van Delden, E.; van Dijk, I.W.; Kok, W.E.; Geskus, R.B.; Sieswerda, E.; Oldenburger, F.; Koning, C.C.; van Leeuwen, F.E.; et al. High risk of symptomatic cardiac events in childhood cancer survivors. J. Clin. Oncol. 2012, 30, 1429-1437. [CrossRef]

9. Eckel, R.H.; Jakicic, J.M.; Ard, J.D.; de Jesus, J.M.; Houston Miller, N.; Hubbard, V.S.; Lee, I.M.; Lichtenstein, A.H.; Loria, C.M.; Millen, B.E.; et al. 2013 aha/acc guideline on lifestyle management to reduce cardiovascular risk: A report of the american college of cardiology/american heart association task force on practice guidelines. J. Am. Coll. Cardiol. 2014, 63, 2960-2984. [CrossRef]

10. World Health Organization. Who/paho regional expert group for cardiovascular disease prevention through population-wide dietary salt reduction. In Protocol for Population Level Sodium Determination in 24-Hour Urine Samples; World Health Organization: Geneva, Switzerland, 2010.

11. Pallazola, V.A.; Davis, D.M.; Whelton, S.P.; Cardoso, R.; Latina, J.M.; Michos, E.D.; Sarkar, S.; Blumenthal, R.S.; Arnett, D.K.; Stone, N.J.; et al. A clinician's guide to healthy eating for cardiovascular disease prevention. Mayo Clin. Proc. Innov. Qual. Outcomes 2019, 3, 251-267. [CrossRef]

12. Zhang, F.F.; Kelly, M.J.; Must, A. Early nutrition and physical activity interventions in childhood cancer survivors. Curr. Obes. Rep. 2017, 6, 168-177. [CrossRef] [PubMed]

13. Armstrong, G.T.; Oeffinger, K.C.; Chen, Y.; Kawashima, T.; Yasui, Y.; Leisenring, W.; Stovall, M.; Chow, E.J.; Sklar, C.A.; Mulrooney, D.A.; et al. Modifiable risk factors and major cardiac events among adult survivors of childhood cancer. J. Clin. Oncol. 2013, 31, 3673-3680. [CrossRef] [PubMed] 
14. Scott, J.M.; Li, N.; Liu, Q.; Yasui, Y.; Leisenring, W.; Nathan, P.C.; Gibson, T.; Armenian, S.H.; Nilsen, T.S.; Oeffinger, K.C.; et al. Association of exercise with mortality in adult survivors of childhood cancer. JAMA Oncol. 2018, 4, 1352-1358. [CrossRef] [PubMed]

15. O'Donnell, M.; Mente, A.; Rangarajan, S.; McQueen, M.J.; O'Leary, N.; Yin, L.; Liu, X.; Swaminathan, S.; Khatib, R.; Rosengren, A.; et al. Joint association of urinary sodium and potassium excretion with cardiovascular events and mortality: Prospective cohort study. BMJ 2019, 364, 1772. [CrossRef]

16. WHO. Guideline: Sodium Intake for Adults and Children; World Health Organization (WHO): Geneva, Switzerland, 2012.

17. WHO. Guideline: Potassium Intake for Adults and Children; World Health Organization (WHO): Geneva, Switzerland, 2012.

18. Drewnowski, A.; Rehm, C.D.; Maillot, M.; Mendoza, A.; Monsivais, P. The feasibility of meeting the who guidelines for sodium and potassium: A cross-national comparison study. BMJ Open 2015, 5, e006625. [CrossRef]

19. Oh, S.W.; Han, K.H.; Han, S.Y.; Koo, H.S.; Kim, S.; Chin, H.J. Association of sodium excretion with metabolic syndrome, insulin resistance, and body fat. Med. (Baltim.) 2015, 94, e1650. [CrossRef]

20. Zhou, L.; Stamler, J.; Chan, Q.; Van Horn, L.; Daviglus, M.L.; Dyer, A.R.; Miura, K.; Okuda, N.; Wu, Y.; Ueshima, H.; et al. Salt intake and prevalence of overweight/obesity in japan, china, the united kingdom, and the united states: The intermap study. Am. J. Clin. Nutr. 2019, 110, 34-40. [CrossRef]

21. Kuehni, C.E.; Rueegg, C.S.; Michel, G.; Rebholz, C.E.; Strippoli, M.-P.F.; Niggli, F.K.; Egger, M.; von der Weid, N.X.; Group, F.T.S.P.O. Cohort profile: The swiss childhood cancer survivor study. Int. J. Epidemiol. 2012, 41, 1553-1564. [CrossRef]

22. Michel, G.; von der Weid, N.X.; Zwahlen, M.; Adam, M.; Rebholz, C.E.; Kuehni, C.E.; Swiss, C.C.R.; Swiss, P.O.G.S. The swiss childhood cancer registry: Rationale, organisation and results for the years 2001-2005. Swiss Med. Wkly. 2007, 137, 502-509.

23. Michel, G.; von der Weid, N.X.; Zwahlen, M.; Redmond, S.; Strippoli, M.P.F.; Kuehni, C.E. Incidence of childhood cancer in switzerland: The swiss childhood cancer registry. Pediatr. Blood Cancer 2008, 50, 46-51. [CrossRef]

24. Belle, F.N.; Popovic, M.B.; Ansari, M.; Otth, M.; Kuehni, C.E.; Bochud, M. Nutritional assessment in childhood cancer survivors: Swiss childhood cancer survival study-nutrition study protocol. JMIR Res. Protoc. 2019, 8, e14427. [CrossRef] [PubMed]

25. Beer-Borst, S.; Costanza, M.; Pechere-Bertschi, A.; Morabia, A. Twelve-year trends and correlates of dietary salt intakes for the general adult population of geneva, switzerland. Eur. J. Clin. Nutr. 2009, 63, 155-164. [CrossRef] [PubMed]

26. Bernstein, L.; Huot, I.; Morabia, A. Amélioration des performances d'un questionnaire alimentaire semi-quantitatif comparé à un rappel des 24 heures [improvement of the effectiveness of a food frequency questionnaire compared with a 24 hour recall survey]. Santé Publique 1995, 7, 403-413.

27. Bernstein, M.; Morabia, A.; Costanza, M.; Landis, J.; Ross, A.; Flandre, P.; Luong, B.; Kumanyika, S.; Sorenson, A.; Localio, R. Nutritional balance of the diet of the adult residents of geneva. Soz. Und Prav. 1994, 39, 333-344. [CrossRef]

28. Marques-Vidal, P.; Rousi, E.; Paccaud, F.; Gaspoz, J.-M.; Theler, J.-M.; Bochud, M.; Stringhini, S.; Guessous, I. Dietary intake according to gender and education: A twenty-year trend in a swiss adult population. Nutrients 2015, 7, 9558-9572. [CrossRef]

29. Morabia, A.; Bernstein, M.; Héritier, S.; Ylli, A. Community-based surveillance of cardiovascular risk factors in geneva: Methods, resulting distributions, and comparisons with other populations. Prev. Med. 1997, 26, 311-319. [CrossRef]

30. Morabia, A.; Bernstein, M.; Kumanyika, S.; Sorenson, A.; Mabiala, I.; Prodolliet, B.; Rolfo, I.; Luong, B. Development and validation of a semi-quantitative food questionnaire based on a population survey. Soz. Und Prav. 1994, 39, 345-369. [CrossRef]

31. Bochud, M.; Chatelan, A.; Blanco, J.-M.; Beer-Borst, S. Anthropometric Characteristics and Indicators of Eating and Physical Activity Behaviors in the Swiss Adult Population, Results from Menuch 2014-2015; Report on Behalf of the Federal Office of Public Health and the Food Safety and Veterinary Office; FSVO: Bern, Switzerland, 2017; Contract Nr. OFSP 16.010537/204.0001/-1476 and contract Nr. FSVO 0714000510. 
32. Belle, F.N.; Chatelan, A.; Kasteler, R.; Guessous, I.; Beck Popovic, M.; Ansari, M.; Kuehni, C.E.; Bochud, M. Dietary intake and diet quality of adult survivors of childhood cancer compared to the general population. bioRxiv 2019. [CrossRef]

33. Essig, S.; von der Weid, N.X.; Strippoli, M.-P.F.; Rebholz, C.E.; Michel, G.; Rueegg, C.S.; Niggli, F.K.; Kuehni, C.E.; for the Swiss Pediatric Oncology, G. Health-related quality of life in long-term survivors of relapsed childhood acute lymphoblastic leukemia. PLoS ONE 2012, 7, e38015. [CrossRef]

34. Federal Food Safety and Veterinary Office FSVO. Swiss Food Composition Database v6.0. Available online: https://www.naehrwertdaten.ch/en (accessed on 3 September 2019).

35. DGE; ÖGE; SGE. D-a-ch-Referenzwerte Für Die Nährstoffzufuhr; Deutsche Gesellschaft für Ernährung (DGE), Österreichische Gesellschaft für Ernährung (ÖGE), Schweizerische Gesellschaft für Ernährung (SGE): Bonn, Germany, 2015.

36. Brown, I.J.; Dyer, A.R.; Chan, Q.; Cogswell, M.E.; Ueshima, H.; Stamler, J.; Elliott, P.; Group, I.C.-O.R. Estimating 24-hour urinary sodium excretion from casual urinary sodium concentrations in western populations: The intersalt study. Am. J. Epidemiol. 2013, 177, 1180-1192. [CrossRef]

37. Ix, J.H.; Wassel, C.L.; Stevens, L.A.; Beck, G.J.; Froissart, M.; Navis, G.; Rodby, R.; Torres, V.E.; Zhang, Y.; Greene, T.; et al. Equations to estimate creatinine excretion rate: The ckd epidemiology collaboration. Clin. J. Am. Soc. Nephrol. 2011, 6, 184-191. [CrossRef] [PubMed]

38. WHO. Obesity: Preventing and managing the global epidemic. In Report of a Who Consultation on Obesity; World Health Organization (WHO): Geneva, Switzerland, 2000.

39. Steliarova-Foucher, E.; Stiller, C.; Lacour, B.; Kaatsch, P. International classification of childhood cancer, third edition. Cancer 2005, 103, 1457-1467. [CrossRef] [PubMed]

40. COG. Long-Term Follow-up Guidelines for Survivors of Childhood, Adolescent, and Young Adult Cancers; Children's Oncology Group (COG): Duarte, CA, USA, 2013; Available online: http://www.survivorshipguidelines.org/ (accessed on 3 September 2019).

41. Willett, W.C.; Howe, G.R.; Kushi, L.H. Adjustment for total energy intake in epidemiologic studies. Am. J. Clin. Nutr. 1997, 65, 1220S-1228S. [CrossRef] [PubMed]

42. Marques-Vidal, P.; Vollenweider, P.; Grange, M.; Guessous, I.; Waeber, G. Dietary intake of subjects with diabetes is inadequate in switzerland: The colaus study. Eur. J. Nutr. 2017, 56, 981-989. [CrossRef] [PubMed]

43. He, J.; Klag, M.J.; Whelton, P.K.; Chen, J.-Y.; Mo, J.-P.; Qian, M.-C.; Coresh, J.; Mo, P.-S.; He, G.-Q. Agreement between overnight and 24-hour urinary cation excretions in southern chinese men. Am. J. Epidemiol. 1993, 137, 1212-1220. [CrossRef] [PubMed]

44. Murphy-Alford, A.J.; White, M.; Lockwood, L.; Hallahan, A.; Davies, P.S.W. Body composition, dietary intake and physical activity of young survivors of childhood cancer. Clin. Nutr. 2019, 38, 842-847. [CrossRef] [PubMed]

45. Zhang, F.F.; Ojha, R.P.; Krull, K.R.; Gibson, T.M.; Lu, L.; Lanctot, J.; Chemaitilly, W.; Robison, L.L.; Hudson, M.M. Adult survivors of childhood cancer have poor adherence to dietary guidelines. J. Nutr. 2016, 146, 2497-2505. [CrossRef]

46. Zhang, F.F.; Saltzman, E.; Kelly, M.J.; Liu, S.; Must, A.; Parsons, S.K.; Roberts, S.B. Comparison of childhood cancer survivors' nutritional intake with us dietary guidelines. Pediatr. Blood Cancer 2015, 62, 1461-1467. [CrossRef]

47. Robien, K.; Ness, K.K.; Klesges, L.M.; Baker, K.S.; Gurney, J.G. Poor adherence to dietary guidelines among adult survivors of childhood acute lymphoblastic leukemia. J. Pediatr. Hematol. Oncol. 2008, 30, 815-822. [CrossRef]

48. Landy, D.C.; Lipsitz, S.R.; Kurtz, J.M.; Hinkle, A.S.; Constine, L.S.; Adams, M.J.; Lipshultz, S.E.; Miller, T.L. Dietary quality, caloric intake, and adiposity of childhood cancer survivors and their siblings: An analysis from the cardiac risk factors in childhood cancer survivors study. Nutr. Cancer 2013, 65, 547-555. [CrossRef]

49. Smith, W.A.; Li, C.; Nottage, K.A.; Mulrooney, D.A.; Armstrong, G.T.; Lanctot, J.Q.; Chemaitilly, W.; Laver, J.H.; Srivastava, D.K.; Robison, L.L.; et al. Lifestyle and metabolic syndrome in adult survivors of childhood cancer: A report from the st. Jude lifetime cohort study. Cancer 2014, 120, 2742-2750. [CrossRef] [PubMed]

50. Hunter, D. Biochemical indicators of dietary intake. In Nutritional Epidemiology, 2nd ed.; Willet, W., Ed.; Oxford University Press: New York, NY, USA, 1998; pp. 174-243.

51. Moosavian, S.P.; Haghighatdoost, F.; Surkan, P.J.; Azadbakht, L. Salt and obesity: A systematic review and meta-analysis of observational studies. Int. J. Food Sci. Nutr. 2017, 68, 265-277. [PubMed] 
52. Leyvraz, M.; Chatelan, A.; da Costa, B.R.; Taffé, P.; Paradis, G.; Bovet, P.; Bochud, M.; Chiolero, A. Sodium intake and blood pressure in children and adolescents: A systematic review and meta-analysis of experimental and observational studies. Int. J. Epidemiol. 2018, 47, 1796-1810. [CrossRef] [PubMed]

53. Tinner, E.M.; Gumy-Pause, F.; Diezi, M.; Bergsträsser, E.; Hengartner, H.; Eisenreich, B.; Brazzola, P.; von der Weid, N.; Tomášiková, Z.; Scheinemann, K. Long-term follow-up after childhood cancer in switzerland: A position statement from the pediatric swiss ltfu working group. Schweiz. Krebsbulletin 2019, 3 , 212-215.

54. COG. Long-Term Follow-up Guidelines for Survivors of Childhood, Adolescent, and Young Adult Cancers (cog-ltfu guidelines); Children's Oncology Group (COG): Duarte, CA, USA, 2018; Available online: http://www. survivorshipguidelines.org/ (accessed on 3 September 2019).

(C) 2019 by the authors. Licensee MDPI, Basel, Switzerland. This article is an open access article distributed under the terms and conditions of the Creative Commons Attribution (CC BY) license (http://creativecommons.org/licenses/by/4.0/). 